\title{
EL CONCEPTO DE FRONTERA EN LA EDAD MEDIA. LA FRONTERA MERIDIONAL DEL REINO DE VALENCIA. SIGLOS XIII-XV*
}

\author{
Juan Antonio Barrio Barrio**
}

\section{EL CONCEPTO DE FRONTERA EN LA HISTORIA MEDIEVAL}

Como afirman tres historiadores franceses tan prestigiosos como Bazzana, Toubert y Guerreau, la preocupación historiográfica y política sobre la frontera arranca en el siglo XIX, en relación con el desarrollo de los nacionalismos y con el descubrimiento de los antagonismos que podían existir entre fronteras estatales y fronteras nacionales, entre fronteras impuestas por las realidades políticas y fronteras subjetivas, deseadas o soñadas. Desde entonces no han dejado de interesar los aspectos históricos y sociopolíticos de las fronteras ${ }^{1}$.

Durante el siglo XIX se produce el registro sistemático de las fronteras nacionales, un registro geométrico preciso de la totalidad del espacio, parcela por parcela (con la elaboración de catastros siguiendo el modelo napoleónico). La idea de frontera se plantea como una línea fija con exactitud casi absoluta, que tiene un valor ontológico al presentar el carácter territorial y cartográfico-geométrico de este tipo de Estado nacional decimonónico.

La compartimentación de la totalidad del espacio terrestre en estados y entidades rodeadas de fronteras lineales es un hecho reciente datado en el periodo de transición entre el siglo XVIII y el siglo XIX. La idea de frontera es europea, salvo la excepción puntual de la muralla china. Fue ignorada por las civilizaciones antiguas, excepto la civilización romana. El concepto de frontera fue difundido en todo el mundo por los europeos a partir de la experiencia colonial ${ }^{2}$.

* La presente aportación ha sido elaborada en el marco del proyecto de investigación "Fundamentos de identidad política: la construcción de identidades políticas urbanas en la Península Ibérica en el tránsito a la modernidad" (HAR2009-08946).

** Universidad de Alicante.

1. A. BAZZANA, «El concepto de frontera en el Mediterráneo Occidental en la Edad Media», Actas del Congreso La frontera oriental nazarí como sujeto histórico (s. XIII-XVI), Almería, 1997, p. 25.

2. M. FouCHER, Fronts et frontières. Un tour du monde géopolitique, París, 1988, p. 29. 
Guerreau afirma que este tipo de noción de frontera no ha existido jamás en la Edad Media. Para Guerreau la frontera en la Edad Media se concibe como una verdadera barrera entre dos sociedades que apenas se superponen o se imbrican entre sí en ningún momento. Y esto se produce solamente en la periferia de la civilización occidental cristiana, donde no se observa ninguna línea, pero existen zonas-tapones ${ }^{3}$.

En la Edad Media la idea de territorialidad es anterior a la consolidación del concepto e identidad de frontera. Como ha puesto de manifiesto García de Cortázar ${ }^{4}$, en una fecha temprana como 1017 se recoge una delimitación territorial entre Sancho García, conde de Castilla y Sancho III, rey de Pamplona. Pero lo que observamos en este escueto documento es una delimitación de lindes y mojones entre sus dos propietarios y señores ${ }^{5}$, no vislumbrándose todavía la percepción de una realidad de frontera, que atañe a instituciones, personas, derechos, bienes, recursos, etc.

Asimismo y en relación con las denominaciones toponímicas y referido al término España y aludiendo a la Crónica de los veinte reyes, escrita entre finales del siglo XIII y principios del siglo XIV, afirmaba Valdeón Baruque "Así pues, aunque en la obra se hiciera alusión a los diversos reinos cristianos existentes en la península Ibérica, la palabra 'España', obviamente, englobaba a todos ellos, tanto como mirada hacia el pasado de época visigoda como en su perspectiva de futuro de unidad política" ${ }^{\prime 6}$. A nuestro juicio la mención al término España en este texto y en las otras crónicas y documentos utilizados, tanto de origen castellano como catalán, por Valdeón en su obra La Reconquista, se circunscribe a una mera expresión de orden territorial, espacial y geográfico como recuerdo del término Hispania, en relación a la provincia del Imperio romano. No hay una implicación que afecte al territorio, al derecho, a la organización institucional y a los hombres que lo ocupan, como puede ser un Estado, una Universitas o una Nación, no hay mención a la Gens, sólo a la tierra. España o Hispania es presentada, por tanto, como un espacio geográfico, no como una entidad nacional o estatal.

Es decir, cuando los autores medievales, en las crónicas castellanas o catalanas, están empleando el término España o en otros textos literarios, lo hacen todos ellos con un único significado que todos entienden y es común para cada uno de ellos y es la noción de territorio, es un concepto meramente geográfico.

3. A. Guerreau, «Frontière», en C. Gauvard, A. Libera y M. ZINK, Dictionnaire du Moyen Âge, París, 2002, pp. 565-566.

4. J.A. GARCÍA DE CORTÁZAR, «De una sociedad de frontera (el valle del Duero en el siglo X) a una frontera entre sociedades (el valle del Tajo en el siglo XII)», Aragón en la Edad Media. Las Sociedades de Frontera en la España Medieval, Zaragoza, 1993, p. 51.

5. A. Ubieto ArtetA, Cartulario de San Millán de la Cogolla (796-1076), Valencia, 1976, Doc. n. 166, pp. 161-162.

6. J. VAldeón BARUQUe, La Reconquista. El concepto de España: unidad y diversidad, Madrid, 2006, p. 148 
Es además un término latino antiguo adaptado y traducido a dos de las principales lenguas romances peninsulares, el castellano y el catalán.

Hay que recordar que "Cuando, en un mismo texto, el latín utiliza alternativamente palabras como signum, figura, exemplum, memoria, similitudo -términos que en francés moderno pueden traducirse todos por 'símbolo'-, no lo hace de manera indistinta, sino que, al contrario, escoge cada una de aquellas palabras con cuidado, pues cada una posee un matiz esencial. Se trata de términos fuertes imposibles de traducir con precisión, a tal punto es vasto y sutil su campo semántico, pero de ninguna manera se trata de términos intercambiables" ${ }^{7}$.

Algo similar sucede con el término y concepto de frontera. El Imperio romano ha utilizado los términos limes o fines, el primero para aludir a las líneas divisorias de las tierras conquistadas y que forman parte de su Imperio y el segundo referido a los "fines" o tierras extremas. En la Península Ibérica, cristianos y musulmanes emplearán un vocablo y un concepto nuevo -frontera-, que en sus diversas acepciones recoge perfectamente la nueva concepción de un espacio frontero, auténtico germen de la sociedad europea occidental y de la ideología de frontera que tanto obsesionó a los hombres del siglo XIX. Atracción por la idea de frontera que permitió la elaboración de una de las grandes obras de reflexión sobre la materia, la que presentó el norteamericano Turner en su obra The Frontier in American History, cuya primera edición fue publicada en New York en $1920^{8}$.

Intentando esbozar una definición de frontera podemos recoger la de Pierre Toubert:

"La frontera nunca es lineal, a no ser que hagamos una abstracción. Es una zona. No es estática más que en apariencia. Siempre es el resultado de un movimiento y en ella se materializa en el espacio un estado de equilibrio precario... El movimiento que crea o sostiene una frontera pone en funcionamiento numerosos componentes de orden distinto (demográficos, económicos, lingüísticos, religiosos, geopolíticos, etc.). La frontera nunca es un término o un simple cierre, sino una membrana viva o... un 'órgano periférico'... La frontera parece segregar, quizá, géneros de vida específicos, como el caso del 'soldado-campesino'. Crea, en todo caso, un estilo de vida cuyos caracteres fundamentales son la violencia, el desprecio por las normas y por los mecanismos de encuadramiento social que predominan en las zonas centrales. El mundo de la frontera es, por excelencia, el del out law" ${ }^{\prime \prime}$.

La numerosa historiografía sobre la evolución de la frontera peninsular ha apuntado la existencia de diversas fronteras que se fueron sucediendo provi-

7. M. Pastoreau, Una historia simbólica de la Edad Media occidental, Buenos Aires, 2006, p. 13.

8. He trabajado con una edición posterior: J. TuRner, The Frontier in American History, New York, 1935.

9. J. LE GOFF, «Centro-Periferia», en J. LE GoFf y J.C. SCHMITT (dirs.), Diccionario razonado del Occidente medieval, Madrid, 2003, p. 151. 
sionalmente en el tiempo. En la vertiente occidental de la Cordillera Cantábrica al Duero, del Duero al Tajo, del Tajo al Guadiana, del Guadiana al Guadalquivir y en la vertiente oriental desde las montañas pirenaicas al Ebro, del Ebro al Turia, del Turia al Júcar, del Jugar al Segura. Pero han sido fronteras variadas y diversas en su tipología, en sus características socioeconómicas, políticas y territoriales y en la duración e intensidad finisecular de cada uno de estos espacios fronterizos.

Lo que tradicionalmente ha venido denominándose Reconquista ha supuesto, a grandes rasgos, un lento proceso de avance de la cristiandad peninsular frente a al-Andalus, de carácter militar, político, humano, social, económico, cultural, ideológico y realizado de norte a sur sobre estos espacios temporal y provisionalmente fronterizos. Aunque esta frontera pudiese ampliarse con lentitud, la idea de temporalidad era latente, dado que entre reyes, condes, nobles, magnates, abades, obispos, etc., existía la permanente conciencia de fomentar el avance de la colonización, de la necesidad de una nueva organización de los espacios a ocupar, a la vez que poder proyectar nuevas conquistas y colonizaciones, la necesidad de instaurar nuevas sedes episcopales e incluso la posibilidad de repartir entre los principales soberanos de los territorios a conquistar en el futuro, mediante tratados como el de Tudillén rubricado en 1151.

La frontera se presenta, por tanto, como un territorio, un espacio socioeconómico, pero también político, religioso, cultural, lingüístico, en permanente evolución y transformación. Uno de los aspectos claves de esta frontera en permanente movimiento fue el concepto acuñado por García de Cortázar, la "organización social del espacio" ${ }^{10}$, como paradigma de esta articulación socioespacial realizada al socaire de los avances espaciales.

Una de las grandes novedades del siglo XIII en la frontera entre el reino de Granada y los dominios cristianos es la singular situación que se va a crear con una demarcación fronteriza estable y por las "específicas condiciones políticas y económicas y por la estabilidad en general de las respectivas posiciones" ${ }^{\prime 11}$. La frontera deja de ser inestable y temporal para convertirse en permanente y estable.

La periferia peninsular, de una de cuyas partes vamos a hablar, el espacio que entre la segunda mitad del siglo XIII y finales del siglo XV fue limítrofe para la cristiandad peninsular pero también para la propia cristiandad mediterráneaoccidental, fue la más original, ya que se observa que la sociedad cristiana que encontramos en fechas posteriores a la Reconquista no sólo difiere de la sociedad del Islam ibérico, sino que, además, es muy distinta de la sociedad cristiana del periodo anterior a la Reconquista. La sociedad de esta zona fue tecnológica-

10. J.A. García de Cortázar y otros, Organización social del espacio en la España Medieval. La Corona de Castilla en los siglos VIII al XV, Barcelona, 1985.

11. M.J. Viguera Molins, «El Reino Nazarí», en J. LYNCH, Historia de España, vol. 9, La Baja Edad Media. Crisis y recuperación, Madrid, 2007, p. 23. 
mente más avanzada e intelectualmente más sofisticada; se encontraba inflamada por un optimismo agresivo y expansionista. Era un mundo dinámico que recibió el impulso de los concejos y de los gremios, de la ley romana y de la escolástica, de las universidades, de la eficacia burocrática y de las instituciones monárquicas, del nacionalismo incipiente, de las lenguas vernáculas, de "modernas" técnicas militares y de nuevas técnicas comerciales, del arte gótico ${ }^{12}$.

\section{EL ORIGEN MEDIEVAL DEL TÉRMINO FRONTERA. INTRODUCCIÓN Y EVOLUCIÓN DEL TÉRMINO EN LA PENÍNSULA IBÉRICA}

Tradicionalmente y a partir de un conocido trabajo publicado por Lucien Febvre en 1928 se ha planteado el origen tardío del concepto frontera, elaborado en los siglos finales de la Edad Media ${ }^{13}$. Al inicio de su trabajo refería la dificultad de definir el término y su ausencia en los diccionarios históricos.

Parece que las advertencias realizadas por Febvre en ese trabajo sobre la escasa definición del término frontera no tuvieron un eco inmediato, ya que hemos realizado una valoración sobre la propia importancia del concepto frontera dentro del vocabulario historiográfico medieval, a partir de una prospección sobre diccionarios de Historia Medieval publicados en las últimas décadas y así comprobar el impacto de la voz frontera en los mismos. Empezando con un clásico, la obra de Pierre Bonnasie aparecida en 1981, Les Cinquante Mots clefs de l'Historie Médiévale, cuya primera edición en castellano fue publicada por Crítica en 1983 con el título Vocabulario Básico de la Historia Medieval. Pues bien, la voz frontera no aparecía, ni tampoco alguna relacionada como centro-periferia, etc., mientras que encontramos términos como ciudad nueva, fragua, gesta, rapiña, etc. En un término tan asociado al concepto de frontera como es la rapiña, sólo vemos una breve aparición de una alusión al término frontera: "Con los carolingios, mejores organizadores que sus predecesores, la rapiña se convirtió en un asunto de estado, quedando en adelante reservada a los especialistas: los guerreros vasallos; además, se practicaba con preferencia (aunque no exclusivamente) en las fronteras" ${ }^{14}$. No sólo llama la atención la ausencia del término frontera, sino también la de otro tan significativo como guerra, mientras que rapiña, que no deja de ser un concepto subsidiario de ambos, aparece resaltado. Parece ser que las modas historiográficas se imponen sobre el sentido común.

12. J. LE GOFF, op. cit., p. 152.

13. L. FebVRE, «Frontière: le mot et la notion», Pour una histoire à part entire, París, 1962, réed. 1982, pp. 12-24. Id., «Frontière: the word and the concept», en P. BURKE, A New Kind of History from the Writings of Lucien Febvre, London, 1973, pp. 208-218.

14. P. Bonnassie, Vocabulario básico de la Historia Medieval, Barcelona, 1983, p. 190. 
Ocho años después, en 1989, Henry Loyn editaba en Londres The Middle Ages. A concise Encyclopaedia, traducido al castellano en 1998 con el título Diccionario Akal de Historia Medieval. En esta obra aparece el término guerra, pero no han sido incluidos conceptos como frontera, centro-periferia o rapiña.

En 1999 aparecía en Francia una obra que ha sido traducida en fechas recientes en España por la editorial Akal, me refiero al Dicctionaire raisonné de l'Occident médiéval ${ }^{15}$, traducido como Diccionario razonado del Occidente Medieval, con ochenta entradas comentadas de forma exhaustiva, no apareciendo la voz frontera, pero sí la entrada centro-periferia elaborada por Jacques Le Goff, en la que se ha incluido una referencia al concepto de frontera, y en la que creo que acertadamente se establece una clara relación entre la capacidad de la Historia para modificar los espacios y el espacio como engendrador de Historia. Y como afirmación de gran valor: "Entre los elementos espaciales que estructuran la evolución de los conjuntos históricos, no hay nada más revelador de esa interacción y de sus transformaciones, que las relaciones entre el centro (o los centros) y la periferia (o las periferias), la observación de cómo evolucionan tales relaciones y cuáles son sus límites"16.

En una obra más reciente y ambiciosa, editada en París en octubre de 2002, bajo la dirección de Claude Gauvard, Alain de Libera y Michel Zink, el Dicctionarie du Moyen Âge, con mil setecientas noventa entradas y con un carácter de integrar todos los aspectos de la Edad Media en un diccionario, se ha recogido la voz frontera elaborada por Alain Guerreau, donde dice "Car, ou bien on trouvait una véritable barrière entre deux societés ne se chevauchant à peu près en rien; et cela se produsait seulament à la périphérie de la chrétienté..." ${ }^{17}$. Sin embargo, en esta obra conceptos como centro-periferia o rapiña no aparecen incluidos. Siendo además la definición del término de frontera muy excluyente en relación a unos espacios periféricos muy concretos.

En nuestro país hay que destacar la obra de José Hinojosa Montalvo, con su muy completo Diccionario de historia medieval del Reino de Valencia en cuatro volúmenes, editado en 2002 y con una amplia definición del término frontera, donde recoge especialmente las aportaciones realizadas en la historiografía de la Corona de Aragón por María Teresa Ferrer i Mallol y por el propio José Hinojosa Montalvo. Una de las definiciones sobre la frontera la presenta como un "espacio de confrontación, de tensiones con la parte opuesta, pero también de 'permeabilidad"' 18 .

Es interesante comparar estas referencias sobre el concepto de frontera en el Occidente cristiano, con la aparición en 1996 en la editorial Akal del Vo-

15. J. Le Goff y J.C. Schmitt (dirs.), Dicctionaire raisonné de l’Occident medieval, París, 1999.

16. J. LE GOFF, op. cit., p. 148.

17. A. GUERreau, op. cit., p. 565.

18. J. Hinojosa Montalvo, Diccionario de historia medieval del reino de Valencia, Valencia, 2002, tomo II, p. 274. 
cabulario de Historia Árabe e Islámica de Felipe Maíllo Salgado, en la que lo más aproximado al concepto occidental de frontera son las voces Dēr-al-harb, como morada de la guerra, el país de la guerra, o sea el resto del mundo que no pertenece el dominio islámico, las tierras de los infieles, contra los cuales los musulmanes se hallan teóricamente en estado de guerra hasta que formen parte del dominio islámico y Dār al-Islām, en alusión al conjunto de territorios en los que rige la sariá, la ley musulmana, y bajo dominio de príncipes musulmanes ${ }^{19}$. Sin embargo, no incluye la definición del vocablo árabe al-farantira.

Sobre estos dos conceptos Alfonso Carmona González afirmaba en el congreso La Frontera Oriental Nazarí, celebrado en 1994, que el derecho islámico clásico divide el mundo en dos partes enfrentadas: la "casa del Islam" (dār alislām) y la "casa de la guerra" (dār al-harb) o "casa de la infidelidad" (dār al$k u f r)$. El uso de ambas denominaciones viene a significar lo mismo: que los territorios donde dominan los infieles están, al menos en teoría, bajo la amenaza del Islam ${ }^{20}$. Desde la época del califato hasta el siglo XII se utilizó el término Tagr como denominación de la frontera con los cristianos, aunque con algunas diferencias. Desde el califato hasta la primera mitad del siglo XI, sin apenas modificaciones. Pero el avance cristiano dejó reducida la utilización del término hacia la segunda mitad del siglo XII a tres zonas fronterizas, el sector occidental o portugués (al-Tagr al-garbī), el sector central o castellano (al-Tagr alawsaț) y el sector oriental o frontera levantina (al-Tagr al-šarq $\bar{\imath})^{21}$. Esta nomenclatura, con la que se había denominado de forma habitual a la frontera musulmana, desaparece completamente en el siglo XIII y será sustituida por un nuevo vocablo, al-farantira, derivado de la arabización del término latino frontaria en opinión de Torres Delgado ${ }^{22}$.

En la cristiandad occidental el concepto y el término de frontera se fue fraguando en los siglos finales de la Edad Media ${ }^{23}$. En Francia aparece entre los siglos XIII y XIV con un uso militar para aludir a la primera línea de los ejércitos en el combate y en el lenguaje arquitectónico referido a una fachada. La primera referencia como concepto geográfico se produce a finales del siglo XIV ${ }^{24}$.

19. F. Maíllo SAlgado, Vocabulario de Historia árabe e islámica, Madrid, 1996, p. 61.

20. A. CARMONA GONZÁlEZ, «La Frontera Islámica: doctrina islámica e instituciones nazaríes», Actas del Congreso La frontera oriental nazari como sujeto histórico (s. XIII-XVI), Almería, 1997, p. 48.

21. C. Torres Delgado, «El territorio y la economía», Historia de España Menéndez Pidal, tomo VIII, p. 507.

22. Ibid., pp. 507-508.

23. Una primera e interesante aportación sobre el concepto frontera fue realizada en el Seminario "Frontière et peuplement dans le mondé Méditerranéen au Moyen Âge", celebrado en Erice (Trapani) en septiembre de 1988: A. BAZZANA, P. GuICHARD y Ph. SÉNAC, «La Frontière dans l’Espagne Médiévale», Castrum, 4. Frontiére et peuplement dans le monde méditerranéen au Moyen âge, Roma-Madrid, 1992, pp. 35-59.

24. G. Constable, «Frontiers in the Middle Ages», en O. Merisalo, Frontiers in the Middle Ages, Louvain-La-Neuve, 2006, p. 3. 
La aparición del término en la Península Ibérica es más temprana que en el resto de Europa, ya que en los territorios de la antigua provincia romana de Hispania la presencia musulmana desde el siglo VIII había convertido a este espacio en la frontera meridional de la Christianitas ${ }^{25}$, frente al mundo bajo dominio islámico.

En el resto de Europa podemos utilizar la precisa imagen con la que Georges Duby retrató la Europa del año 1000, como un espacio dividido que no tenía verdaderas fronteras ${ }^{26}$.

La primera mención conocida historiográficamente del término frontera, que aparece en la documentación latina, se encuentra en el primer testamento de Ramiro I de Aragón redactado en torno al año 1059²: "Castros de fronteras de mauros qui sunt pro facere" ${ }^{28}$. Esta primera aparición conocida del sustantivo frontera ha sido analizada por Philippe Sénac ${ }^{29}$, que cita las sucesivas y siguientes apariciones del término frontera en la documentación aragonesa. En 1061 en el segundo testamento de Ramiro I se vuelve a mencionar "in castellos de fronteras de mauros qui sunt per fare et in castellos qui sunt in fronteras per facere"; un año después se hace en una carta real: "et tu quod cavallero et franco sedeas quomodo homine debet esse in frontera francho et cavallero". Hasta 1105 no vuelve a aparecer el vocablo, recogido en una donación al abad del monasterio de San Juan de la Peña: "quanto ibi tenebamus frontera"30.

La primera constatación realizada por Sénac de la aparición del vocablo frontaria en latín en la Corona de Aragón es en un documento de 1202, una donación real referente a unas fortalezas: "in frontaria sarracenorum". En otras dos donaciones reales, una del mismo año y otra del año 1209, aparece copiada la misma expresión: "in frontaria sarracenorum" 31.

Resulta paradójico observar que en estas primeras apariciones del término frontera, el vocablo aparece en su acepción románica "frontera" inserta en textos totalmente latinos: "...et alia pro cabtibos et pro pontes facere et ad castros de fronteras

25. Para el concepto de Christianitas vid. R. BARTLETT, La formación de Europa. Conquista, colonización y cambio cultural, 950-1350, Valencia-Granada, 2003.

26. G. Duby, La época de las catedrales. Arte y sociedad, 980-1420, Madrid, 2002, p. 20.

27. Ph. SÉNAC, «La frontera aragonesa en los siglos XI y XII. Pro defensionem christianorum et confusionem sarracenorum», Territorio, Sociedad y Poder, 4, 2009, pp. 151-166.

28. Ph. SÉNAC, «Ad castros de fronteras de mauros qui sunt pro facere. Note sur le premier testament

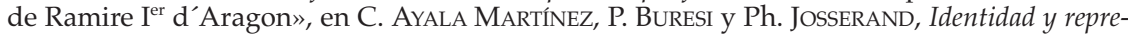
sentación de la frontera en la España medieval (siglos XI-XIV), Madrid, 2001, p. 205.

29. Ph. SÉNAC, «Frontiére et reconquête dans l'Aragon du XI ${ }^{\mathrm{e}}$ siècle», en Ph. SÉNAC (ed.), Frontières et espaces pyrénéens au Moyen âge, Perpignan, 1992, pp. 47-60. Id., "Islam et chrétienté dans 1’Espagne du Haut Moyen âge», Studia Islamica, 89, 1999, pp. 89-105. Id., «La frontière aragonaise aux $\mathrm{XI}^{\mathrm{e}}$ et $\mathrm{XII}{ }^{\mathrm{e}}$ et la chose», Cahiers de civilisation médiévale, 42, 1999, pp. 259-272. Id., «Ad castros de fronteras de mauros...» $\mathrm{y}$ «La frontera aragonesa en los siglos XI y XII...».

30. Ph. SÉNAC, «Frontiére et reconquête...», p. 209.

31. Ibidem. 
de mauros qui sunt pro facere ${ }^{\prime \prime 32}$, mientras que el nuevo vocablo latino frontaria, creado para aludir a este nuevo concepto, aparecerá en textos latinos en fechas posteriores a la de esta primigenia aparición en la documentación aragonesa.

Georges Martin ha estudiado el concepto de frontera en el Cantar del Mio $\mathrm{Cid}$, afirmando que la frontera acaba donde comienza la tierra de moros ${ }^{33}$. Sobre este tema también se pronunció Lucien Febvre que afirmaba que en esta obra términos utilizados en la Península Ibérica, como límite, confín, no aparecen mientras que el vocablo frontera está incluido en el Poema con el significado de región o territorio que separa a dos pueblos, pero que no aparece referido a fortificaciones o un sistema militar de defens ${ }^{34}$.

Hemos realizado una revisión del texto y hemos localizado una aparición puntual y escasa del término frontera, exactamente en tres ocasiones.

“Tres reyes veo de moros, derredor de mi estar,

No lo detardedes los dos id pora alla;

tres mill moros llevedes con armas de lidiar,

Con los de la frontera que vos ayudaran.

Prendedmelo a vida, aduzidmelo delante,

Porque seme entro en mi tierra derecho me habra a dar.

Tres mill moros cabalgan y piensan de andar,

Ellos vinieron a la noche en Sogorbe posar;

Otro dia mañana piensan de cabalgar,

Vinieron a la noche a Çelfa posar.

Por los de la frontera piensan de enviar;

No lo detienen, vienen de todas partes" ${ }^{\prime 35}$.

Más adelante y en la misma obra:

"Ya es aguisado, mañana se fue Minaya,

Y el Campeador, con su mesnada.

La tierra es angosta y sobejana de mala,

Todos los dias a mio Çid aguardaban

Moros de las fronteras y unas gentes estrañas

Sano el Rey Fariz, con el se consejaban

Entre los de Teca y los de Terrer la casa,

Y los de Calatayud, que es mas honrada;

Asi lo han asmado y metudo en carta"36.

32. Ibidem, p. 220.

33. M. GonzÁlez Jiménez, «Relación final», en C. Ayala Martínez, P. Buresi y Ph. Josserand, Identidad y representación..., p. 294.

34. L. FEBVRE, «Frontière: the word and the concept...», p. 217.

35. P. Salinas (ed.), Cantar de Mio Cid, Barcelona, 1997, p. 126.

36. Ibidem, pp. 144 y 146. 
En el testamento de Ramiro I de Aragón el término aparecía en una ocasión y en el Cantar del Mio Cid terminado de redactar en 1207 el sustantivo frontera se escribe en tres ocasiones, tanto en su forma singular como en plural.

También ha sido localizada la aparición del término en su acepción latina frontaria en la obra de Rodrigo Ximénez de Rada, que denomina en la primera mitad del siglo XIII a todos los territorios conquistados por Castilla y a las plazas fuertes avanzadas con el término frontaria ${ }^{37}$.

Rastreando los corpus documentales latinos que pueden ser consultados, como es el caso de la excelente base de datos CODOLGA ${ }^{38}$, hemos realizado una búsqueda de los términos limes, fines y frontaria, todos ellos alusivos a cuestiones de límites espaciales extremos y a la propia frontera en la documentación latina gallega. El término limes no ha aparecido en ninguna ocasión. El término fines aparece en quince documentos que van del año 883 al año 1320.

En el primer texto la mención a un territorio extremo parece nítida:

"manet notissimum quod ratione retinetur ambiguum, eo quod dum extremi fines prouincie Gallecie ab antiquis pre impulsionem sarracenorum in occidentali plaga" ${ }^{39}$.

Mientras que el término frontaria ha aparecido en cuatro ocasiones ${ }^{40}$. La primera en el año 941 y en relación a una cuestión de lindes agrarios y sería una aparición anterior a la del testamento de Ramiro I y en lengua latina, "quos habeo de parentorum meorum. do uobis ipso agro cum frontaria et sua prestantia in giro usque in termino uestro, quomodo" 41 . El sustantivo frontaria en este documento entronca con la evolución del término latino fronte, empleado para designar a las tierras que confrontan ${ }^{42}$, lo que confirmaría la hipótesis de que el término frontera deriva de los términos del latín clásico frons, frontis ${ }^{43}$. En la documentación latina leonesa, la evolución del término frontaria sigue un desarrollo similar, con origen en los términos latinos frons, frontis y con un progreso crono-

37. C. Torres Delgado, op. cit., p. 508.

38. Corpus Documentale Latinum Gallaeciae (http:/ / balteira.cirp.es/codolga/). Sobre la base documental CODOLGA vid. F. LÓPEZ ALSINA, «La red y las fuentes documentales medievales: el ejemplo de CODOLGA», Aragón en la Edad Media. Pescar o navegar: la Edad Media en la red. Sesiones de trabajo. Seminario de Historia Medieval, Zaragoza, 2005, pp. 19-40.

39. A. López Ferreiro, Historia de la Santa A.M. Iglesia de Santiago de Compostela, II-VII, Santiago de Compostela, 1899-1904, Doc. 15, pp. 29-30.

40. “Caceres, Emerita a labore Sarracenorum, ac vigiliis, et desudatione tenendi frontariam cesaverint, hoc est cum civitates alie, vel Castella hunc laborem" (1171) en A. LóPEz FERREIRO, op. cit., Doc. 45, pp. 111-114. "omnibus directuris suis, videlicet cum omnibus exitibus et pascuis et frontariis suis imperpetuum; et ipsi concedunt mihi unum casale in Barran" (1220) en M. Romaní MARTínez, Colección diplomática do Mosteiro cisterciense de Santa María de Oseira (Ourense) 1025-1310, Santiago de Compostela, 1989, 3 vols., Doc. 200, pp. 199-200.

41. J.M. ANDrade Cernadas, O tombo de Celanova: estudio introductorio, edición e índices (ss. IXXII), Santiago de Compostela, 1995, 2 vols., Doc. 452, p. 614

42. Ph. SÉNAC, «Ad castros de fronteras de mauros...», p. 212.

43. Ibidem, pp. 211-212. 
lógico parecido, ya que en 1209 se constata la primera mención al término latino frontaria con significado de parte limítrofe de un reino ${ }^{44}$.

La última referencia en la documentación gallega al término latino frontera es en relación a un documento de 1228, la que alude expresamente a una frontera con los musulmanes: "qua sepulturam habuerint peregrini. et alias duas tercias in usus frontarie contra mauros assignet. precipimus quoque omnibus iusticiariis nostris ut hanc" ${ }^{\prime 5}$.

En la patrología latina hemos encontrado una referencia al término frontaria en la obra de Petrus Vallis ${ }^{46}$, escrita en 1218, en la que aparece el término frontaria en relación a la frontera con los musulmanes.

"Quod si forte in persona comitis nollet Ecclesia ipsius petitionem audire, petir et rogat hoc idem pro filio; ita tamen quod puer nihilominus satisfaciat personaliter pro excessibus, vel in frontaria Saracenorum cum militibus eundo in subsidium Christianorum, vel in partibus transmarinis, secundum quod Ecclesia melius arbitrabitur expedire" ${ }^{47}$.

Parece ser que es en Castilla donde aparece con fuerza el término y el concepto de "frontera" en el contexto de la conquista de Andalucía y la creación de una de las primeras instituciones específicas de la frontera, el Adelantado de la frontera ${ }^{48}$.

Mi planteamiento, que entronca con el original realizado por Lucien Febvre, es que el término y concepto de frontera es tardío en el mundo medieval. Trasladando esta hipótesis a la Península Ibérica y en el contexto del proceso histórico de avance territorial denominado Reconquista, hay que diferenciar entre una visión historiográfica que analiza la evolución de las fronteras en la Península Ibérica y otro que propone la aparición del concepto y término de frontera en el mundo medieval y en el contexto de dicha expansión territorial. Hasta la segunda mitad del siglo XIII y principios del siglo XIV todos los esfuerzos de monarcas y nobles se orientaban a "la consolidación de la frontera mediante un control de sus núcleos básicos de poder" ${ }^{49}$. Hasta el final de las campañas de Fernando III y de Jaime I no existieron fronteras definitivas. Como ha afirmado Mitre, hay que diferenciar entre el paso de una idea de frontera móvil a una realidad de frontera estática ${ }^{50}$.

44. P. PÉrez GonZÁlez, «Frontera», en Diccionario latino-romance del Reino de León (en prensa). Gentileza del autor.

45. J.V. GonZÁlez GonZÁlez, Alfonso IX, Madrid, 1944, 2 vols., Doc. 519, pp. 619-620.

46. P. Vallis Cernail, Petri Monachi Coenobii Vallium Cernaii Historia Albigensium et sacri belli in eos anno 1209 sucepti duce et principe Simone de Monteforti. Patrología Latina, vol. 213.

47. Ibidem, "Petitiones regis Arragonensium ad praelatos in concilio apud Vaurum congregatos".

48. B. VÁzQuez CAMPos, «'Frontera' y Adelantamientos en época de Alfonso X», Historia. Instituciones. Documentos, 30, 2003, pp. 535-557.

49. A. Rodríguez LÓPEZ, La consolidación territorial de la monarquía feudal castellana. Expansión y fronteras durante el reinado de Fernando III, Madrid, 1994, p. 153.

50. E. Mitre FernándeZ, «La cristiandad medieval y las formulaciones fronterizas», en E. Mitre FERNÁNDEZ y otros, Fronteras y fronterizos en la historia, Valladolid, 1997, p. 9. 
El proceso denominado Reconquista fue un constante avance territorial sobre bases de dominio temporales y en ocasiones de control incierto, planteado hacia la futura consolidación de una frontera, hacia un statu quo aceptado por todos los poderes implicados en el reparto y a la organización del poder sobre los territorios que los cristianos eran capaces de gestionar en la Península lbérica. Un dominio que hasta bien entrado el siglo XIII no llegó a quedar fijado o anclado en un espacio específico o concreto.

Lo que se produjo después de la conquista de Andalucía, de Murcia y del reino de Valencia, y especialmente a partir del tratado de Almizra en 1243 y la construcción del último estado musulmán, fue la creación entre esos espacios, el reino nazarí de Granada, el reino de Murcia y el reino de Valencia, de la primera frontera estable y anclada en el espacio de la Península Ibérica. Una frontera que sería perfilada con bastante precisión en la Sentencia Arbitral de Torrellas de 1304 y la adenda o modificación realizada un año después con el acuerdo de Elche. Es en esos márgenes espaciales y territoriales donde se desarrolla el concepto de frontera, la vida de frontera, las instituciones de frontera, la economía de frontera, etc.

Al igual que sucede con la forja de identidades, fenómeno que supone que la creación de una identidad implica la necesidad de crear la identidad contraria, la alteridad sólo puede desarrollarse en el reconocimiento mutuo de la existencia del otro. El origen y creación del concepto y término de frontera en los siglos finales de la Edad Media es un fenómeno como hemos planteado novedoso, frente a lo que había sido la erección del limes romano en época de Marco Aurelio, sobre los planteamientos ideológicos auspiciados ya en época del emperador Augusto, cuando se planteó una política territorial más hacia la contención que hacia la expansión. En todo caso el anclaje del limes romano a partir del siglo II d.C. es una acción unilateral pensada, decidida, acordada y ejecutada por parte de las autoridades imperiales romanas. El desarrollo de la frontera medieval peninsular a partir del siglo XIII es la consecuencia del establecimiento y consolidación de dominios territoriales llevado a cabo por las potencias implicadas: Corona de Castilla-León, Corona de Aragón y reino nazarí de Granada. El establecimiento de una línea fronteriza suponía la aceptación y reconocimiento mutuo de cada una de las partes de dicho contorno fronterizo y el asumir un statu quo territorial a partir de un determinado momento.

Torres Delgado plantea el establecimiento de la frontera nazarí como fenómeno paralelo a la creación del Estado granadino y llevado a cabo desde 1246 hasta 1260, fecha en que, a su juicio, queda realmente establecida la frontera del reino nazarí de Granada ${ }^{51}$. Acción que lleva pareja la creación de una frontera similar en territorio castellano, a la vez que entre castellanos y aragoneses se había fijado desde el Tratado de Almizra una primera frontera. La primera consecuencia es la creación de la frontera, que será estable pero no ina-

51. C. Torres Delgado, op. cit., p. 509. 
movible. Torres Delgado, en esta línea, ha elaborado una interesante cronología que muestra la evolución de la frontera nazarí granadina desde su primera fase de establecimiento (1246-1260) hasta su desaparición en $1492^{52}$.

La historiografía que se ha ocupado del estudio de las identidades nacionales, territoriales y fronterizas, ha desdeñado o minusvalorado la posición de los reinos medievales ante la toma de conciencia en cada una de estas cuestiones. Se ha objetado que la identidad nacional surgió con claridad a partir del siglo XIX, sobre la base de principios como la precisa y definida territorialidad y las fronteras de una nación ${ }^{53}$, o a través de los postulados de Anderson, que afirmaba que gracias a los modernos y eficaces sistemas de comunicación, verbigracia la producción impresa masiva, se facilitaba la homogeneización cultural e ideológica de una nación ${ }^{54}$. Hermet argumenta que es difícil documentar la conciencia colectiva de las poblaciones medievales, privadas de acceso a la escritura y prácticamente sin contacto los unos con los otros ${ }^{55}$. Estas aseveraciones parten, una vez más, de un profundo desconocimiento de la documentación y la sociedad medieval. Los archivos locales de los municipios europeos conservan miles de testimonios que permiten reconstruir los sistemas identitarios de los dirigentes urbanos de las villas y ciudades europeas al menos desde el siglo $\mathrm{XIII}{ }^{56}$. Por otra parte el pretendido analfabetismo de toda la sociedad medieval debería empezar a ser cuestionado, ya que además de la gente que podía llegar a leer, el resto de los habitantes de las ciudades eran informados puntualmente de las disposiciones normativas o de otras noticias a través de la transmisión oral de la información. La supuesta falta de contacto de unos con otros es otro tópico falso sobre la Edad Media. El apogeo del mundo urbano a partir del siglo XI y el desarrollo de rutas de peregrinación como el camino de Santiago, convirtió a los europeos en una sociedad viajera y comunicada. Los caballeros-guerreros, los comerciantes, los marinos, los mensajeros de las ciudades, se desplazaban de unos lugares a otros en el desempeño de su actividad y se ponían en contacto con gentes que vivían en lugares alejados, con los que intercambiaban conocimientos, ideas, tecnologías, etc. ${ }^{57}$. En este sentido fue decisiva la difusión del papel, como material escriturario y el potente desarrollo de la relación epistolar entre ciudadanos a nivel privado y entre los diversos cen-

52. Ibidem, pp. 509-511.

53. G. Hermet, Histoire des nations et du nationalisme en Europe, París, 1996.

54. B. ANDERSON, Comunidades imaginadas: Reflexiones sobre el origen y la difusión del nacionalismo, México, 2005.

55. G. HERMET, op. cit. p. 41

56. Sobre la identidad urbana vid. J.A. Jara Fuente, G. MARTin e I. Alfonso Antón (coords.), Construir la identidad en la Edad Media, Cuenca, 2010.

57. En descargo de Hermet se puede alegar que el fenómeno de la transmisión de la información en la Edad Media sigue siendo un tema poco investigado. Un congreso reciente se ha ocupado de esta novedosa cuestión, C. Boudreau, K. FiAnu, C. GAUvard y M. Hébert, Information et société en Occident à la fin du Moyen âge, París, 2004. 
tros de poder a nivel público. Como colofón a estas relaciones epistolares en los siglos finales de la Edad Media se produjo el origen de las relaciones diplomáticas entre los diferentes centros de poder, con el envío de sus mensajeros o embajadores que permitían poner en contacto ideas y corrientes de pensamiento entre unas ciudades y otras, sin olvidar el papel de las cortes y parlamentos medievales, que también favorecieron estos intensos contactos entre los representantes de las oligarquías dirigentes de los centros urbanos europeos.

Creo que a finales de la Edad Media se forjaron de forma seminal los primeros conceptos sobre frontera y nación, pero ideas y términos que eran desarrollados por las clases dirigentes y que podían tener una incidencia escasa entre el resto de las capas sociales. Precisamente, y siguiendo postulados como los de Anderson, estimamos que la principal aportación del siglo XIX es la plena madurez y la consolidación de las ideas sobre nación, territorio o frontera entre las capas dirigentes y la posterior asimilación, con mayor o menor lentitud, por las masas populares, de valores como nación, patria, etc.

Los procesos de construcción de identidades han sido más intensos y prolongados en el tiempo de lo que algunos historiadores han llegado a vislumbrar. Lo que en principio fue una conciencia de identidad que podía quedar limitada a las fronteras de una ciudad, se extendió en adelante hacia la abstracción, a las fronteras de un Estado que, por otra parte, la mayoría de los habitantes no habían visto jamás ${ }^{58}$.

Para Rodríguez López el término frontaria es utilizado de forma exclusiva para designar los límites territoriales entre cristianos y musulmanes y nunca las franjas limítrofes que separaban Castilla de los demás reinos cristianos $^{59}$. Para la mayoría de autores que se han ocupado de estudiar la frontera entre el reino nazarí de Granada y el reino de Castilla, el análisis de la frontera se circunscribe de forma exclusiva a dicha demarcación fronteriza ${ }^{60}$.

En el reino de Valencia, la Gobernación de Orihuela fue un espacio fronterizo o demarcación natural creado a partir de la firma del Tratado de Torrellas en 1304. En este territorio el término y el concepto frontera tienen igual aplicación para la frontera con los musulmanes como para la frontera con los cristianos del reino castellano de Murcia.

En un documento de Pedro IV dirigido a las autoridades de la villa de Orihuela, concediendo un privilegio sobre la posesión de caballo armado de sus ha-

58. G. Messadié, Historia del antisemitismo, Buenos Aires, 2001, p. 221.

59. A. Rodríguez LóPEz, La consolidación territorial de la monarquía feudal castellana. Expansión y fronteras durante el reinado de Fernando III, Madrid, 1994, p. 259.

60. Criterio también recogido en un libro de reciente aparición, J. RoDRíGUEz MolinA, La vida de moros y cristianos en la frontera, Alcalá la Real, 2007. El título en su expresión genérica debería aludir a todas las fronteras que se desarrollaron en la Península Ibérica, incluidas las que afectaron a territorios de la Corona de Aragón. El desarrollo del libro se centra de forma exclusiva y muy especialmente en la frontera "entre Castilla y Granada" (vid. Contraportada). 
bitantes, el monarca indica con precisión la posición de frontera de sus habitantes respecto a los enemigos musulmanes del reino nazarí de Granada y del reino de Castilla. Este texto recoge una precisa definición de la frontera que afectaba a la villa de Orihuela. La primera alude a los musulmanes del reino Nazarí de Granada y la segunda a la frontera con el reino de Murcia perteneciente a la Corona de Castilla.

“Com per algunes causes e rahons justes e com hauents memoria de molts e diverses agradables serveys a nos feits per los habitants en la vila de Oriola com encara esguardants que la dita vila es situada en frontera axi dels enemichs de la fe xristiana ço es de la morisma de Granada com encara del reyalme de Castella e que necessaria cosa a la poblaçio guarda e defensio de la dita vila e dels termens de aquella que los habitants en aquella e en sos termens no solament sien per nos e per lo dit nostre primogenit e per los oficials nostres e seus regits e tractats justament mas encara favorable e graciosa" ${ }^{61}$.

En un documento de 1382 se precisa la peculiar situación de frontera de la villa de Orihuela.

"Attressí como Oriola sie hedificada en loch de frontera de moros, hoc encara en frontera de castellans més que altre loch alcú del regne e senyoria del senyor rey d'Aragó..." ${ }^{62}$.

Alfonso V en una carta enviada al rey de Castilla afirmaba que, "Rey muy caro e muy amado primo. En la villa de Hellín del vuestro Regno de Castiella frontera del nuestro Regno de Valencia..."63.

En un documento similar dirigido al gobernador del reino de Valencia della Sexona, y en relación a una queja presentada por su hermano Juan, rey de Navarra, que poseía tierras y vasallos en el reino de Valencia, el rey indicaba al gobernador que, "... a instancia del illustre Rey de Navarra infant d'Arago e de Sicilia, nostre molt car e molt amat frare considerants que la mes de la sua terra que aquell posseex en Regne de Valencia es prop la frontera de Castella..." 64 .

En un privilegio de Juan II emitido más de cien años después del privilegio de Pedro IV, que recogía una precisa definición de la frontera de la Gobernación de Orihuela, se detalla una definición similar e incluso más explícita.

Nos encontramos en la recta final de la Edad Media en 1469. Han pasado doscientos años desde que el territorio fue pacificado por Jaime I en la campaña que realizó en el reino de Murcia para sojuzgar la revuelta mudéjar que había estallado en Andalucía y en el reino de Murcia ${ }^{65}$. En algunos aspectos no había cambiado casi nada y el statu quo se mantenía en la Gobernación de Orihuela, con una frontera que, desde las importantes modificaciones de 1304 con el Tra-

61. Archivo Municipal de Orihuela (AMO). Libro becerro, f. 94 r-v. (1364, diciembre, 20).

62. M.T. FERRER I MALlol, Organització i defensa d'un territori fronterer: la governació d'Oriola en el segle XIV, Barcelona, 1990, doc. 210 (1382, mayo, 12), p. 516.

63. Archivo del Reino de Valencia (ARV), Real, 35, ff. 101v-102r. (1428, 01, 24).

64. ARV, Real, 35, ff. 142r. $(1428,12,11)$.

65. J. TORRES FOnTES, La reconquista del reino de Murcia en 1266 por Jaime I de Aragón, Murcia, 1967. 
tado de Torrellas, seguía perfilando una situación de triple frontera para la población cristiana de las localidades de realengo como la ciudad de Orihuela, con la numerosa población mudéjar que residía en los núcleos señoriales de la propia Gobernación, en zonas densamente pobladas como el valle de Elda, con la presión del cercano reino nazarí de Granada y con la frontera directa en torno al río Segura con el reino castellano de Murcia:

"Nós, don Joan, etc. Segons per part de vosaltres, amats e feels nostres los jurats e prohòmens de la nostra ciutat d'Oriola, nos és stat humilment significat, la dita ciutat e governació d'Oriola que és dellà Saxona és en la frontera de Castella e de Granada e poblada de molts lochs de mores e christians que són de senyoria de barons e cavallers, de què s'esdevé molt sovint que en los límits de la dita governació entrent gents per fer dans als poblats en aquella molt poderosament" 66 .

Unos pocos años antes, en febrero de 1460, la tensión entre las autoridades de la ciudad de Orihuela, capital de la Gobernación, era extrema ante la situación que se estaba viviendo en el cercano valle de Elda, con una elevada población mudéjar, ante la posibilidad de establecer una morería real en la villa cristiana de Monforte, lo que podía conllevar la despoblación y el abandono del lugar de los cristianos y a juicio de los regidores oriolanos poner en peligro la integridad física de la población cristiana de la Gobernación de Orihuela $^{67}$. Así lo exponían en el memorial que preparaban para, a través de un mensajero, hacer llegar a Juan II sus temores:

"Item informara la dita majestat e notificara aquella com la vall d'Elda segons sa majestat ha vist sia tota poblada de moros la qual per esser contigua ab Regne de Castilla e quasi de Granada continuament en aquella venen adalids del dit Regne de Granada los huns per pasar moros del dit Regne e altres per matar robar e cativar xristians per los quals adalids es stat vist esser fets en la dita vlla molts dans...per causa del loch de Monfort qui es poblat de xristians qui esta en lo mig del dit vall qui ja en lo temps que aquesta terra fon recuperada e conquistada de moros se dona horde lo dit loch restas en la dita vall poblada de xristians per ço que los moros del dit vall no poguesen cobrir o donar obra que moros de Granada venguesen per fer los dits dans..." ${ }^{68}$.

El texto refleja de forma elocuente una amenaza real, aunque a lo mejor algo exagerada por parte de las autoridades. Pero nos interesa resaltar de este documento la expresión de una identidad y conciencia desarrollada por la oligarquía dirigente oriolana sobre la situación fronteriza de un territorio, la Gobernación de Orihuela, y sobre todo de las ciudades, villas y lugares poblados por cristianos que tenían que coexistir con morerías que tenían una elevada población mudéjar. Todos estos diferentes aspectos confluyen finalmente en la elaboración de una identidad colectiva, en la consolidación de una comunidad

66. ARV, Real, reg. 291, ff. 135v-136r. (1469, junio, 12).

67. J.A. BARRIO BARRIO, «La difícil convivencia entre cristianos y musulmanes en un territorio fronterizo. La gobernación de Orihuela en el siglo XV», Sharq Al-Andalus, 13, 1997, pp. 9-26.

68. Archivo Histórico de Orihuela (AHO), Contestador, n. ${ }^{\circ} 31$, ff. 29r-v. (1460, febrero, 25). 
cristiana, sobre las bases de unos antepasados conquistadores que son glorificados por haber "recuperado y conquistado a los moros esta tierra", sobre la permanente existencia de un frontera que requiere de sucesivos esfuerzos bélicos por parte de los individuos que sustentan y reafirman esta comunidad.

En el Cuatrocientos los miembros de las oligarquías urbanas son los descendientes de los antiguos combatientes de la frontera, que mantienen en su memoria las hazañas de sus antepasados y de ellos mismos contra los musulmanes granadinos y contra los castellanos, como se jactan de recordar en sus peticiones de privilegios a la Corona.

Todo este programa de construcción de un aparato propagandístico para el ejercicio del poder en el ámbito local, y que llevaba implícito la elaboración de un discurso político que reafirmaba la identidad de la urbe cristiana, era tejido y reafirmado por la elite dirigente, que tras la conquista cristiana fue elaborando una identidad que afirmaba y reiteraba su hegemonía, la necesidad de sus servicios y la gratitud que debía emanar hacia estos linajes que eran los ostentadores de la memoria y la historia de la nueva comunidad cristiana y que estaba integrada plenamente en la Corona de Aragón.

\section{LA FRONTERA DEL REINO DE VALENCIA. GÉNESIS Y ANTECEDENTES EUROPEOS Y PENINSULARES}

Queremos recordar una afirmación vertida por Miguel Ángel Ladero Quesada, en su obra La formación medieval de España, "La España en la que vivimos hoy se hizo en aquellos siglos: en su territorio, en sus regiones, en su forma geohistórica. Ningún otro período de la historia española tiene tanta importancia en estos aspectos. Pero además, la conquista, el dominio y la regionalización del territorio son sólo el aspecto externo, el más visible; hay otros muchos más complejos y profundos -sociales, políticos, culturales- que hacen de la plena Edad Media el tiempo en que nacieron o maduraron verdaderamente la inmensa mayoría de los elementos que componen la realidad histórica originaria de la España actual" ${ }^{\prime 69}$.

La creación y posterior desarrollo de la frontera meridional valenciana a principios del siglo XIV con la sentencia arbitral de Torrellas se inserta en un contexto europeo expansivo, conquistador y colonizador ${ }^{70}$. La situación peninsular de forja permanente de fronteras, cuando en un territorio convergen dos espacios con diferente hegemonía religiosa o de civilizaciones entre dos zonas limítrofes, que van desplazándose de norte a sur, de la Cordillera Cantábrica al Duero, del Duero al Tajo, del Tajo al Guadiana, del Guadiana al Guadalquivir, desde las

69. M.A. Ladero Quesada, La formación medieval de España. Territorios, Regiones, Reinos, Madrid, 2004, pp. 16-17.

70. R. BARTLETT, op. cit. 
montañas pirenaicas al Ebro, del Ebro al Turia, del Turia al Júcar, del Jugar al Segura, etc., segregó fronteras variadas y diversas en su tipología, en sus características socioeconómicas, políticas y territoriales y en la duración e intensidad finisecular de cada uno de estos espacios fronterizos. Es la situación característica en la Península Ibérica entre los siglos VIII al XV, en la tradicionalmente denominada Reconquista, en la que coexistieron una sociedad feudal cristiana frente a una sociedad urbana islámica con una organización tributaria y mercantil.

Este doble conflicto, como ha sido definido por Le Goff, se focaliza en dos grandes espacios. Por una parte, los conflictos o tensiones entre zonas periféricas externas, Cristiandad-Islam, y por otra los que se desenvuelven en zonas periféricas internas (guerra entre cristianos), como los enfrentamientos entre ingleses e irlandeses, galeses y escoceses, franceses y bretones, franceses y occitanos, franceses y flamencos, polacos y caballeros teutónicos, etc. ${ }^{71}$, a los que había que añadir los desarrollados en la Península Ibérica entre castellanos y navarros, castellanos y aragoneses, castellanos y portugueses, etc.

La propia denominación contemporánea del espacio fronterizo llama la atención, términos como "la banda gallega" (referido al espacio fronterizo entre la zona oriental del reino de Sevilla y el reino de Portugal) ${ }^{72}$, "borders" (en relación a la región de la frontera escocesa, entre los territorios controlados por los señores escoceses y los territorios bajo dominio señorial inglés) $)^{73}$ o el propio de "frontera" utilizado en la frontera meridional valenciana, nos deben hacer reflexionar sobre la diferente percepción que tuvieron los contemporáneos del hecho fronterizo.

En la documentación medieval conservada en el Archivo de la Corona de Aragón, en el Archivo del Reino de Valencia o en archivos locales de la Comunidad Valenciana, el término frontera aparece en centenares de documentos con la denominación catalana frontera y con la denominación latina frontaria ${ }^{74}$. Incluso en un documento de 1459 el notario ha escrito mal el término latino escribiéndolo como fronteria ${ }^{75}$.

En este decisivo periodo se construyeron nuevos territorios, identidades y espacios singulares. Fue una acción que, sin ser totalmente improvisada, partía de la creación de un nuevo diseño geo-histórico, en el que uno de los ejes fundamentales fue la relación que mantuvieron las dos grandes potencias peninsulares, Castilla-León y la Corona de Aragón, desde el momento en que

71. J. LE GOFF, op. cit., pp. 146-157.

72. Vid. J.A. Pérez MaCías y J.L. CARriazo Rubio (eds.), La Banda Gallega. Conquista y fortificación de un espacio de frontera (siglos XIII-XVIII). I Curso de Historia y Arqueología Medieval, Huelva, 2005.

73. A. Goodman, «La Frontera Escocesa c. 1300-1603», III Estudios de Frontera. Convivencia, defensa y comunicación en la Frontera, Jaén, 2000, pp. 331-343.

74. J.F. Niermeyer y C. VAN DE KIEFT, Mediae Latinitatis Lexicon Minus, Leiden-Boston, 2004. El conocido léxico apunta la siguiente definición del término frontaria, traducido como frontera o también como "frontside of a strip of land".

75. ARV, Real, reg. 283, f. 9r. (1459, abril, 16). 
decidieron actuar a partir de un acuerdo común sobre los territorios a conquistar, lo que se plasmó en el diseño de la frontera común, realizado entre mediados del siglo XII y comienzos del siglo XIV, a medida que podían impulsar este proyecto de conquista feudal de al-Andalus, en un contexto ibérico de superioridad cristiana. Esta expansión territorial pactada se va a plasmar en una relación de tratados que reflejaban la evolución de la relación de fuerzas entre los dos estados firmantes. Esta lista de tratados se abre con el de Tudillen de 1151 y se cierra con el de Elche de 1305.

Riera i Melis ha explicado de forma precisa el proceso iniciado en 1151 y concluido en 1305. La firma del Tratado de Tudillén en 1151 se inserta en un contexto característico de la Península Ibérica pero asociado al entorno del feudalismo de la Europa Occidental. Para los señores y guerreros peninsulares, se trataba de aprovechar el repliegue almorávide, acentuando su presión militar sobre al-Andalus. Esta agresividad, como había sucedido con las Cruzadas, o con la expansión alemana hacia el Este, o la de los ingleses hacia Gales y Escocia o la de los Cruzados normandos hacia Occitania y Bretaña, obedecía a causas muy diversas. Entre los factores comunes a los guerreros europeos, hay que destacar la consolidación de las estructuras feudales, la escalada social y política de una casta de terratenientes armados que gestionaban sus crecientes señoríos con un planteamiento económico de carácter extensivo. Para los señores, guerreros profesionales, la forma más accesible y sencilla de incrementar sus rentas y, en consecuencia, su poder, consistía más en incorporar nuevas tierras y nuevas jurisdicciones y títulos que en incrementar la productividad y la intensificación de la actividad económica en su señorío.

Las monarquías europeas, con el objetivo de incrementar el patrimonio real y rebajar la tensión interna de los feudales, procuraban orientar la agresividad militar de éstos y su hambre de tierras hacia fuera, hacia los espacios fronteros y periféricos de la cristiandad occidental, donde estos guerreros podían ser impulsados e impelidos hacia la guerra feudal conquistadora. En la Península Ibérica se abría a los reyes y guerreros feudales un amplio territorio susceptible de ser conquistado en los territorios de al-Andalus. Esta superioridad militar cristiana respecto al Islam en general y al-Andalus, en particular, derivaba de factores externos más o menos comunes a toda la cristiandad occidental, como la creciente articulación económica y política de los reinos peninsulares con el Occidente europeo, el incremento de relaciones con la Santa Sede y la difusión del espíritu de Cruzada y la génesis de las órdenes militares. La interacción de estos factores va a atraer a la Península, al igual que sucedía en otras zonas de Europa, contingentes importantes de guerreros, monjes, mercaderes e incluso campesinos, que van a dinamizar la economía, la técnica, la cultura y especialmente van a reforzar el potencial militar y colonizador del conjunto de los cristianos $^{76}$.

76. A. RIERA MELIS, «La delimitació del sector meridional de la frontera entre la Corona CatalanoAragonesa i el regne de Castella (1151-1305)», Acta Historica et Archaeologica Medievalia, 25, 2003-2004, pp. 73-92. 


\section{EL AVANCE DE LA FRONTERA MERIDIONAL VALENCIANA}

El avance de la frontera meridional valenciana y su definitiva consolidación a principios del siglo XIV está en estrecha relación con el proceso de conquista y creación del reino de Valencia realizado en la primera mitad del siglo XIII, que se vio retrasado tanto por la creciente presión almohade sobre las fronteras meridionales cristianas peninsulares como por la orientación ultrapirenaica de la política aragonesa, que había motivado un menor interés hacia la conquista de las tierras peninsulares del Levante.

El primer problema quedaba aparentemente solucionado con la derrota almohade en Las Navas de Tolosa (1212). Pero los frutos de esta batalla no se hicieron inmediatos, en el caso de la Corona de Aragón, por la prematura muerte de Pedro el católico un año después, dejando como nuevo soberano a Jaime I, un niño, en medio de graves enfrentamientos nobiliarios.

Sólo con la renuncia a la empresa occitana y con el apoyo expreso de la nobleza y la burguesía, pudo Jaime I acometer las conquistas de Mallorca y el reino de Valencia. Este apoyo va a permitir a Jaime I proyectar hacia las tierras del sur el hambre de rentas de los señores, el ansia de beneficios de los mercaderes, el deseo de tierras y trabajo de los campesinos y artesanos empobrecidos, el deseo de cristianización del clero, etc.

Jaime I buscaba con esta conquista consolidar su poder e incrementar su prestigio como soberano en el marco de un estado feudal arraigado, con la idea de neutralizar las exigencias políticas de la nobleza con la entrega de nuevas tierras y rentas, espolear el crecimiento de la burguesía con una ampliación de empresas y mercados y aumentar el protagonismo de la Corona de Aragón en el contexto internacional, especialmente en el Mediterráneo y en la Península Ibérica.

Lo más destacado de la acción conquistadora de Jaime I es que no integró ni Mallorca en Cataluña, ni Valencia en Aragón, sino que creó con las tierras recientemente conquistadas nuevos reinos.

Enric Guinot en Els limits del Regne constata varios hechos interesantes que paso a exponer a continuación sobre la construcción territorial y política del reino de Valencia ${ }^{77}$.

La idea generalizada de que el reino de Valencia ha mantenido una configuración territorial inalterada y constante a lo largo de los siglos ha supuesto que la representación cartográfica del reino valentino no haya sido muy afortunada y que, en consecuencia, ha prevalecido el planteamiento de que los pueblos y comarcas que conformaron este espacio en la época medieval han quedado casi inalterados hasta los tiempos más recientes. Es una visión estática de la geografía histórica valenciana.

77. E. GuINOT, Els límits del regne: el procés de formació territorial del País Valencià medieval, 12381500, València, 1995. 
La constitución política del reino de Valencia se produce en 1240, momento de la redacción de los primitivos fueros. Pero durante los dos siglos siguientes, XIV y XV, tuvieron lugar cambios significativos en sus límites, con diversos altibajos en el listado de los pueblos y villas que lo conformaban. El reino de Valencia como unidad política que comprendía del río Cenia hasta Biar (Tratado de Almizra, 1244) primero, y hasta Guardamar desde 1304, no había existido ni antes ni durante la época musulmana.

La formación territorial del reino de Valencia fue el resultado de un proceso histórico en el que Jaime I creó ex novo un nuevo reino que incorporar a su Corona, equiparable, por tanto, a los existentes de Cataluña y Aragón. No se puede confundir esta realidad del siglo XIII con las voluntades políticas nacionalistas de las sociedades contemporáneas.

El reino de Valencia en el siglo XIII fue una tierra de frontera para millares de emigrantes en busca de mejores formas de vida, y un botín espectacular para una parte de ellos sin muchos escrúpulos. El proceso de configuración de la geografía histórica y la dinámica temporal de la incorporación de los pueblos valencianos al conjunto político del reino eran una historia hasta hace poco desconocida o incompletamente elaborada, y que a pesar del acierto de esta obra de Guinot, todavía hay pequeños aspectos que precisan una aclaración. En la construcción del reino de Valencia, entre 1232 y 1304 serán incorporados territorios de los reinos taifas de Valencia, Denia, de Murcia o de territorios de Xàtiva, o de la propia Orihuela donde se había creado un territorio islámico independiente. Todos estos territorios se incorporaron a una entidad única y nueva, el reino de Valencia, que recibía el nombre de una de estas entidades políticas o reinos de taifas ${ }^{78}$.

La frontera meridional valenciana quedó constituida con la creación del reino de Valencia y el establecimiento en el sur de este nuevo reino de una frontera, que lo era tanto de la Corona de Aragón como del reino de Valencia y en parte de la propia cristiandad occidental. Fue un espacio, entre la segunda mitad del siglo XIII y finales del siglo XV, periférico para la cristiandad occidental, pero también para la cristiandad mediterránea.

A lo largo de estos dos siglos y medio se desarrollaron en la frontera meridional valenciana una serie de procesos sociales y económicos nuevos, diferentes a los de la etapa musulmana, que se enmarcan en el marco social y económico hispanocristiano feudal, con sus propias peculiaridades en las comarcas meridionales, pero al mismo tiempo homogéneos con respecto a la evolución histórica desarrollada en el resto del reino de Valencia, en el que se incluyen estas comarcas. Estos siglos no fueron de inmovilismo, sino todo lo contrario, de gran movilidad en todos los órdenes, lo que obliga a un análisis de larga duración.

78. Ibidem, pp. 8, 9, 10 y 13 . 
La conquista cristiana tuvo como primera consecuencia una transformación del poblamiento y del espacio. La primera actuación de la monarquía fue la implantación de nuevas villas reales, como centros de colonización cristiana realizada sobre un sustrato poblacional mudéjar mayoritario.

Se busca el control de las rutas y caminos interiores, de la costa frente a posibles ataques piráticos, y la consolidación de la frontera, cumpliendo estas poblaciones una clara función militar, además de la económica ${ }^{79}$.

Tras la primera fase de conquista militar de las tierras valencianas, entre 1233 y 1245, se procedió a la repoblación cristiana en núcleos poblacionales agrupados, mediante la vía de la implantación de villas y aldeas fundadas por la Corona con la concesión de cartas pueblas. Denia y Onteniente reciben sus cartas pueblas en 1245 y 1249 respectivamente, siendo, por tanto, las primeras localidades del norte de la provincia de Alicante pobladas por cristianos. Hitos decisivos fueron la implantación de la villa de Cocentaina realizada por Jaime I en 1251 y la de Alcoy que se produce en 1256. Con estas actuaciones Jaime I iniciaba una primera fase de creación de pequeños núcleos fortificados, sustentados por colonos cristianos como base poblacional, pero también política, económica, social y militar para controlar el territorio recientemente conquistado a los musulmanes. En esta primera etapa anterior a la revuelta mudéjar de 1276-1277, también fueron colonizadas por cristianos las localidades de Bocairente (1256), Xixona (1267), Guardamar (1271) y Beniarrés (1275). Tras la revuelta mudéjar se procedió a fundar pequeños núcleos estratégicos para la defensa cristiana del territorio, como Penàguila que recibió de Pedro III su carta puebla en 1278, para beneficiar como pobladores a los peones que habían defendido el castillo roquero durante la revuelta musulmana.

Fue decisiva la creación de una red de ciudades fronterizas, gobernadas por una oligarquía de guerreros, de caballeros villanos. Centros urbanos en los que la función militar, en palabras de Dennis Menjot, estaba hipertrofiada, dado que la frontera era potencialmente peligrosa, por lo que las ciudades situadas en estas zonas limítrofes constituyeron apoyos logísticos en la organización defensiva del Estado, pudiendo erigirse en cabeceras de distritos militares, como en el caso de Murcia o en el caso de Orihuela. Esta militarización tuvo enormes consecuencias políticas, sociales, económicas y espaciales y paisajísticas, traducida esta última consecuencia en la construcción y reforzamiento de un sistema defensivo cuya construcción y mantenimiento corrió a cargo de las arcas municipales ${ }^{80}$.

La conquista de Jaime II del reino de Murcia en 1296 y el fin del conflicto bélico iniciado con la Corona de Castilla con la firma de la sentencia arbitral de Torrellas en 1304 tuvieron notables e importantes consecuencias para el reino

79. J. Hinojosa Montalvo, Las tierras alicantinas en la Edad Media, Alicante, 1995, p. 8.

80. D. Menjot, Dominar y controlar en Castilla en la Edad Media, Málaga, 2003, pp. 117-135. 
de Valencia, que ampliaba su frontera y que pasaba de estar situada en localidades ubicadas en la montaña, como la villa de Alcoy, a fijar la línea de frontera en villas de llanura como Orihuela o Elche y en localidades marítimas como Alicante y Guardamar.

Estos centros urbanos se convierten en el paradigma de la ciudad-frontera $^{81}$, con un predominio de las actividades agrícolas y guerreras, la preponderancia de una oligarquía de guerreros ${ }^{82}$ y con un reparto social de sus habitantes en función de criterios económicos y militares: caballeros -baja noblezay peones -ciudadanos ${ }^{83}$. Tras la conquista, los centros urbanos que canalizaban la colonización cristiana recibieron un "derecho de frontera", con un fuero inicial y sucesivos privilegios ${ }^{84}$ que confirmaban y reiteraban la hegemonía del grupo guerrero dirigente y que con diferentes tipos de franquicias y exenciones daban generosas facilidades a la instalación de una inmigración muy abierta, que se podía nutrir de individuos perseguidos por delitos menores en sus localidades de origen y a los que se les garantiza la inmunidad por acudir a poblar localidades fronterizas, cuya vida cotidiana resulta difícil y peligrosa por las algaradas o los ataques corsarios que pueden sufrir y el riesgo de poder caer en las redes del cautiverio o la esclavitud.

De los modelos generales de ciudades de frontera propuestos por Lacarra, Gautier-Dalché o Ruiz de la Peña, y ampliados y resumidos por Menjot, las villas y ciudades de la Gobernación de Orihuela tenían una estructura similar en los aspectos ya referidos, pero en su evolución y desarrollo económico, social y político superaron algunos de los sencillos esquemas de la articulación de las ciudades de frontera fundadas en León y Castilla durante los siglos XI y XII. A partir del siglo XIV, y sobre todo durante el siglo XV, las ciudades de frontera de la Gobernación de Orihuela evolucionaron de una inicial movilidad social a la constitución de oligarquías cerradas, de la relativa sencillez del gobierno municipal inicial se pasó a un gobierno municipal complejo en su estructura institucional y organigrama político, con una burocracia avanzada y la culminación en el desarrollo político con una cancillería municipal al servicio del grupo dirigente, cada vez menos guerrero y transformado en un grupo rector de la ciudad e imbuido en la actividad política, funcionarial y de gobierno. De una sociedad ganadera-agrícola se evoluciona a una sociedad agrícola-industrial. El reparto inicial en dos categorías sociales, caballeros -baja nobleza- y peones

81. Ibidem.

82. J.A. BARRIO BARRIO, «Las élites políticas urbanas en la gobernación de Orihuela. Los sistemas de creación, acceso y reproducción del grupo dirigente en un territorio fronterizo», Anuario de Estudios Medievales, 32/2, 2002, pp. 707-808.

83. J.A. BARRIO BARRIO, «La articulación de una oligarquía fronteriza en el mediodía valenciano. El patriciado de Orihuela. Siglos XIV-XV», Revista d'Història Medieval, 9, 1998, pp. 105-126.

84. J.A. BARRIO BARRIO, «Los privilegios reales. Centralización estatal y transmisión de la política real», en Id. (ed.), Los cimientos del Estado en la Edad Media, Alcoy, 2004, pp. 119-156. 
-ciudadanos-, también sufrió la correspondiente transformación con la nueva división creada en el siglo XV entre ciudadanos mayores y ciudadanos menores, que matizaba en tres manos la inicial y dual organización del poder municipal.

En esta división en tres "manos", ya advertida por el franciscano Francesc Eiximenis en su obra El Regiment de la Cosa publica de finales del XIV, la primera estaba compuesta por la baja nobleza y los ciudadanos honrados que viven de forma honorable de sus rentas. En el segundo grupo se encuentran los simples ciudadanos: juristas, notarios, mercaderes y pañeros y todos cuantos poseen grandes riquezas. El tercer grupo es el formado por el "común" o la menestralía: plateros, herreros o coraceros. Descripción que muestra con bastante exactitud la situación que se dio en ciudades como Valencia desde 1329, Mallorca desde 1351, en Lleida desde 1388, en Orihuela desde 1445 y en Barcelona desde $1455^{85}$. Con algunas peculiaridades que refieren la diferente situación de cada centro urbano. Así, en Barcelona la mano mayor estaba formada exclusivamente por los ciudadanos honrados y en Orihuela sólo por la baja nobleza.

En el sur del reino de Valencia la frontera fue uno de los elementos más característicos en la organización social del espacio, ya que al menos hasta finales del siglo XV se mantuvo el peligro exterior de la amenaza granadina y la presión castellana. Para localidades con población mayoritaria cristiana como Orihuela y Alicante, la inquietud que provocaba la frontera interior representada por las comunidades mudéjares de la Gobernación estuvo viva hasta la expulsión de los moriscos en 1609.

\section{RESUMEN}

El objetivo del trabajo es analizar la evolución del concepto frontera en la Península Ibérica en la Edad Media. El concepto frontera alude a una interpretación historiográfica así como a un término que fue creado en la Península Ibérica en su variante latina, romance y árabe. Los vocablos frontaria, frontera y al-farantira aludían a una nueva forma de organizar y entender la distribución espacial entre reinos o entre civilizaciones. El concepto limes de época imperial romana había quedado obsoleto ante las nuevas modalidades de delimitación territorial entre los incipientes estados medievales, por lo que fue necesario establecer una nueva forma de entender la organización política y territorial de los espacios que a partir de los siglos finales de la Edad Media va a atañer a instituciones, personas, derechos, bienes, recursos, etc. Utilizamos como observatorio privilegiado de estudio la frontera meridional de la Corona de Ara-

85. R. NARbona VizCaíno, Valencia, municipio medieval: poder político y luchas ciudadanas (12391418), Valencia, 1995; Id., «Algunas reflexiones sobre la participación vecinal en el gobierno de las ciudades de la Corona de Aragón (ss. XII-XV)», Res publica. Revista de la historia y del presente de los conceptos políticos, 17, 2007, pp. 113-150. 
gón, que a partir de la segunda mitad del siglo XIII quedó establecida en el recién conquistado reino de Valencia.

Palabras clave: frontera, Frontaria, al-Farantira, territorio, delimitación.

\begin{abstract}
This work analyses the evolution of the concept of "frontier" in the Iberian Peninsula in the Middle Ages. The concept of "frontier" refers to a historiographic interpretation as well as a word developed in the peninsula in the Latin, Romanic and Arabic variants. The words "frontaria" and "al-farantira" would refer to a new form of organising and understanding the spatial distribution between kingdoms or civilisations. The concept "limes", of Imperial Roman period was considered obsolete considering the new ways of delimiting territories between the new medieval states, which made it necessary to establish a new way of understanding political and territorial organisations from the late Middle Ages. This understanding will include institutions, people, rights, patrimony, resources, etc. As a privileged observatory, we use the Crown of Aragon southern frontier, which was established in the second half of the $13^{\text {th }}$ century for the newly conquered kingdom of Valencia.
\end{abstract}

Key words: frontier, Frontaria, Al-Farantira, territory, delimitation. 